\title{
EMBO backs single electronic repository
}

[PARIS] The European Molecular Biology Organization (EMBO) is supporting the launch of a global web repository for literature in the life sciences, in cooperation with the US National Institutes of Health (NIH).

The concept of a database that would be freely accessible to all — called 'E-Biomed' has been instigated by Harold Varmus, the director of the NIH. He has proposed that it be taken forward via an international coalition (see Nature 398, $735 \& 399,8-9 ; 1999$ ).

EMBO will "aim to be a partner in the start-up international governing body that will be formed by interested parties," says Frank Gannon, executive director of EMBO. "EMBO's position is that a single searchable location for all scientific data of relevance to life sciences is a very desirable goal."

Under the proposal, EMBO scientists would help to administer an assessment procedure for the repository. The computing infrastructure for the European arm would be handled by the European Molecular Biology Laboratory's outstation, the European Bioinformatics Institute, in Cambridge, UK.

EMBO's vision of the repository differs from that of 'E-Biomed', however. For example, it wants the repository not to be restricted to the biomedical literature, but to include all of the life sciences, including plant biology and biotechnology.

According to internal EMBO documents, the organization's main concern is that the 'E-Biomed' proposal could result in a "loss

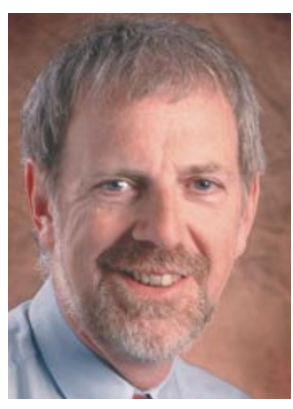

of quality control" that could seriously damage molecular biology.

The 'E-Biomed' proposal allows authors to submit to either an unrefereed e-print server or a peer-reviewed server - in effect, a large electronic journal. $\begin{array}{ll}\text { Gannon: concern over } & \text { Buality control. }\end{array}$ an unrefereed repository, and also questions the need for fullblown peer review within 'E-Biomed'.

An unrefereed site along the lines of the Los Alamos e-print server in physics will not work in biology, asserts Gannon. The interpretation of biological research is much more subjective - and controversial - than that of physics, he says, and is highly dependent on the controls carried out.

"I think that the material on an e-print server for biology which is unrefereed, unassessed or 'un-quality controlled', really has no more status than press releases," says Gannon.

Instead, EMBO proposes that all papers submitted to 'E-Biomed' should be "assessed" for acceptance by a mosaic of learned societies to ensure that they constitute reasonably sound science. In practice, scientists submitting to the repository could, for example, send their paper to EMBO.

$\mathrm{EMBO}$ would send the paper to one of its 1,000 members who, according to Gannon, would ask: "Are there good reproducible methods? Are the data presented clearly? Are the conclusions reasonable, and not extrapolated to folly?" Papers meeting these criteria would receive an 'EMBO approved' stamp.

"There is a big difference between this and refereeing in the journal sense," he says. "A referee in a journal is also asking: is this sound? But they are integrating it into a scale of quality as judged by universal interest, interest for readers, and ranking compared with other material submitted."

Under the EMBO proposal, the repository would not introduce such a peer-review system. It argues that this would be unnecessarily complicated, and is best left to existing journals.

Gannon predicts that journals of low quality and circulation will disappear, but the top journals will remain. "The leading journals carry a message that this is work that has been upgraded/improved/approved by the refereeing system; they will be seen as a real asset in a way that has been taken for granted so far."

The need, says Gannon, is not to reinvent the journals system within 'E-Biomed', but to link in the journals, perhaps by licensing material from them. "We are very anxious to defend top journals and scientific societies; to lose that at a stroke would be bad for science."

DeclanButler

\section{Commission to report on overhaul for French research structure}

[PARIS] The creation of a 'parliament' of French scientists, to act as a bridge between research bodies and governments, is likely to be among the recommendations expected this month from a parliamentary commission on French research set up earlier this year by the prime minister, Lionel Jospin.

The parliamentary commission headed by members of the National Assembly, Pierre Cohen and Jean-Yves Le Déaut - wound up at the end of last month with a national colloquium at the Sorbonne in Paris.

The outcome is expected to provide a basis for restarting discussions about reforms that have stalled for almost a year because of stiff opposition in the research community to proposals from the research minister, Claude Allègre.

The commission itself is not expected to make its recommendations to the government until later this month. As a result, the detailed status of the proposed 'parliament' of scientists remains unclear But Le Déaut says it will assess national research programmes and comment on the distribution of funding.

Allègre's proposals to make the universities the central plank in the French science system, in place of the national research agencies such as the Centre National de la Recherche Scientifique (CNRS), are unlikely to be backed by the commission.

Le Déaut argues that "the respective roles of the agencies and universities are well established: the agencies should steer nationally and the universities locally", but he supports greater cooperation between the two.

Several delegates at the Sorbonne colloquium argued that many universities lacked the capacity of the research agencies to organize national research strategies. Some called for a complete reform of the university system.

This is already essential, say some observers, because a shift in research effort from research agencies to universities is taking place, as recruitment to universities is almost three times that at the agencies.
Closing the meeting, Le Déaut said there was a need to end 'old boy' networks, reduce bureaucracy, and modernize what he described as the excessively top-down structure of evaluation and other commissions.

But he argued that these problems were not restricted to the universities, as they were also common within agencies. Indeed, the commission seems likely to back plans by Allègre for an overhaul of research evaluation, with greater input from scientists in other countries. Evaluation of laboratories and staff would be carried out separately, with the former shifting to a system based more on selection of research projects.

The commission seems unlikely to reject a proposal to create a single employment status of lecturer/researcher. At the moment, some agency scientists enjoy full-time research while their colleagues in the universities struggle under heavy teaching loads. It is also expected to recommend a reduction in teaching loads and greater opportunities for transfers between the universities and research agencies. Eric Glover 